\title{
Integrating Lifecycle Thinking in Asset Management Through BIM: Opportunities for the Water Sector
}

\author{
Emiliya Suprun, Rodney A. Stewart, Sherif Mostafa, Oz Sahin and \\ Edoardo Bertone
}

\begin{abstract}
The water industry worldwide has been gradually transitioning towards digital asset management practices. Australia is no exception. However, these practicesareoftencomplicatedbyalackofconsistentmodelsforgatheringandmaintainin $\mathrm{g}$ up-to-date asset information across the industry. There is a need for innovative digital platforms and asset management solutions for making decisions that suit the increasing needs of the water sector. Building Information Modelling (BIM) can potentially be the conduit to asset management databases as it goes well beyond 3D models developed for use in the design and construction phase. The overarching goal of this research was to address the water industry challenge of implementing BIM to integrate digital data for the facility lifecycle as well as to provide information and decision support to asset management, and operation and maintenance. A number of workshops with asset managers and maintenance operators were held on the basis of a case study of a bulk water supply company in Australia. Stakeholders discussed specific expectations for the visualisation of information to ensure that data is used, understood and managed over the whole lifecycle. The barriers to the implementation of digital techniques for the purpose of efficient asset management were also explored.
\end{abstract}

Keywords Asset information model, Asset management, BIM, Lifecycle thinking, Water industry

\section{Introduction}

This study is timely in an Australian context where the Federal and State Governments are establishing policies and guidelines for the use of Building Information Modelling (BIM) and related digital engineering technologies on Government projects with both new and existing assets. For example, one of the objectives set by the Queensland Government for the development of BIM practices is "to promote consistency and interoperability in the information requirements for state infrastructure projects to facilitate a harmonized approach for industry" (DSDMIP 2018).

BIM is much more than just 3D design. BIM is an object-based approach to organizing information that can be described as a digital representation of physical and functional characteristics of a facility and its aspects (ABAB 
2018). BIM is also a knowledge resource for information that allows for each project participant to share their discipline-specific data within a single project model (Wong et al. 2018). As a result, digital data derived from BIM acts as a reliable unified point of reference for decisions during assets lifecycle.

The water industry continually relies on the public sector infrastructure, such as drainage systems or water treatment plants (WTP), which are typical projects delivered by contract private water and construction companies in Australia. According to the Australian Bureau of Statistics (ABS 2017), the water industry in Australia had an estimated annual revenue of \$22.71 billion, adding \$13.06 billion to the Australian economy in 2015-2016. It goes without saying, that safe water quality and appropriate sanitation are essential to sustaining economic growth and the high standard of living in Australia. Hence, the importance of BIM for water infrastructure has become greater than ever before (Yin et al. 2014). However, where some industries are already successfully incorporating BIM workflows into their business processes and distribution networks, the water industry has been relatively slow to adapt to this change.

In recognition of the lack of digital integration in the sector, this study addresses the readiness of the Australian water industry to implement BIM throughout the facility lifecycle for making decisions that suit the overall duration of the lifecycle. The study also aims to capture the key decisions required in asset management, by considering lifecycle thinking during the design, construction, operation and maintenance (O\&M) phases of water facilities. The challenges of the water industry to BIM implementation along with the digital data integration for the facility lifecycle and efficient asset management were discussed on the basis of a case study of a bulk water supply company in Australia.

\section{The Role of Information in Asset Management}

In the majority of cases, BIM models are developed for use in the design and construction phase, however, the O\&M of a facility take up most of its lifecycle (Wong et al. 2018). According to Akcamete et al. (2010), the O\&M of a building equate to $60 \%$ of the overall costs and time of a project. Hence, the potential benefits of using BIM for facility operations are compelling. First of all, BIM enables provision of the asset management systems with information relevant at the time of operation of a certain asset.

Potential BIM benefits for asset management are well documented in the literature (Becerik-Gerber etal. 2012; Love etal. 2014; Hafeez etal. 2015; Araszkiewicz 2017; Hosseini et al. 2018):

- enhanced capacity for maintaining and monitoring an asset over its entire lifecycle;

- proactive interventions and earlier decision making;

- better informed maintenance activities; 
- more efficient asset management especially in the operational phase;

- better predictive analytics;

- an ability of all organization's departments to access high quality digital data about the assets;

- better understanding of an organization's needs by BIM compliant partners;

- facilitation of required savings;

- better risk management throughout design, construction, operation and maintenance.

Nevertheless, the utilization of BIM during O\&M of the facility is falling behind the BIM implementation for design and construction (Akcamete et al. 2010). First of all, efficient management at the operation stage requires integrating a very large amount of information and data accumulated at earlier stages of the facility lifecycle, with information that appear in the course of a facility maintenance. Moreover, the effects of management during O\&M stages result from decisions taken at earlier stages. As such it is critical that asset management processes can be fully engaged in the BIM process in order for the potential benefits and savings to be fully realized in operation.

It is also very important to use harmonised and consistent data formats, standards, systems and tools across the asset life cycle. Structured asset information for the commissioning, and operation and maintenance are used to supply data to the asset owner or operator to populate decision-making tools and asset management systems. In order to improve the information exchange and issuing of information that supports the delivery of a project, a common data environment $(\mathrm{CDE})$ is recommended to be used (ABAB 2018). It allows a company to keep not only assets created in BIM environment but also documentation related to the assets. For the purpose of data transfer the data handovers are to be in open data format, such as industry foundation classes (IFC), BuildingSMART, or Construction Operations Building information exchange (COBie) standard (ABAB 2018).

\section{Approach}

A literature review and a case study serve as a basis for unlocking opportunities for innovative asset management solutions suited to the increasing needs of the water sector; assessing current systems for managing water asset information; identifying the key asset information requirements for effective management of specific key bulk water distribution assets and; establishing directions to follow in further research. The literature review included an assessment of the current methods adopted for utilizing project and asset information within the international water industry firstly, and then an Australian sector specifically. The study is aligned with the national and international requirements for integrating lifecycle thinking in asset 
management (e.g. ISO 55000) and information management (e.g. ISO 19650) (ISO 2014, 2018a, b).

Dawood and Vukovic (2015) state that a lack of managers' expertise is one of the key barriers to BIM implementation. Various problems the water industry faces while integrating digital technologies with asset management practices were discussed on the basis of a case study of a bulk water supply company in Australia. Two workshops with asset managers and maintenance operators were held. Stakeholders were asked to specific expectations for the visualisation of information to ensure that data is used, understood and managed over the whole lifecycle. Some of the questions that guided the workshops included:

- How mature is the water sector in terms of BIM implementation?

- What are the main obstacles to increasing BIM use in the water industry?

- What potential benefits does BIM offer for the water sector?

- Howwellarethemodelsfromthewaterprojectsintegratedwithassetmanag ement systems?

- What could potentially drive wider use of BIM for water projects?

- What is the most important next step to drive wider BIM utilization in the water sector?

\section{Case Study}

As mentioned above, the barriers to implementation of digital techniques for the purpose of the efficient asset management were discussed on the basis of a case study of a bulk water supply company in Australia. The company provides drinking water to more than 3 million people. It also provides essential flood mitigation services, managing catchment health and providing irrigation services to more than 1000 customers. Overall, the company manages more than $\$ 10$ billion of water supply assets and parts of the natural catchments to supply their services. These assets include WTPs, dams, weirs, reservoirs, pumps and pipelines. The company's functions are but not limited to:

- carrying out water activities;

- supplying water services;

- developing water supply works;

- improving the supply, delivery and quality of water;

- promoting efficient use of and investment in water infrastructure;

- ensuring the safe, secure and reliable supply of water.

With numerous construction and engineering partners working on a multitude of water infrastructure projects and providing various formats of design documentation information, the company requires integrated and/or interoperable digital asset management tools to ensure efficient operation 
and maintenance of its current and future planned infrastructure, plant and expansive natural assets. Moreover, the Queensland Government takes the first steps towards implementation of a policy to gain the maximum advantage of digital engineering and has committed to implementing the use of BIM on all major state infrastructure projects by 2023 (DSDMIP 2018). Hence, this study's outcomes aim to prepare the water company to strategically position themselves to transition to digital engineering in order to align with upcoming legislative requirements. It is also expected to improve the company's ability to make strategic and sustainable investments throughout the lifecycle of its assets as well as to help the company to build capacity related to the adoption of structured digital data to make better informed decisions.

In relation to integrating different digital platforms throughout the facility lifecycle, the following challenges were identified through a number of workshops:

- a very diverse asset base;

- the usability, accessibility and relevance of the data in the systems;

- the quality of the digital data in the systems;

- the ability to find asset information;

- the use of unrelated spreadsheets to complete basic asset management functions;

- the duplication of information;

- the lack of information sharing;

- the understanding the information flows associated with the end to end processes;

- an inconsistent asset information framework;

- information might become distorted or irreversibly before the operation and maintenance stage.

Stakeholders also agreed that information exchange through the water asset lifecycle remains fragmented and the asset management is disconnected from the design and construction phases. This proves the necessity of including asset managers in the entire lifecycle of a facility. During multiple discussions, it was concluded that understanding the key needs of asset managers enables to define detailed scope and priorities amongst information and data necessary for the efficient asset management. This in turn aids the design of a precisely formulated effective BIM implementation roadmap to be used to trigger the digital data collection requirements during the lifecycle of the project. As a result, the governance and the ongoing maintenance of asset information become more efficient; there is only one 'source of truth', i.e. database that links all asset related data sources and enables accurate reporting; asset management decisions are based not only on 'expert judgement'; the ability to run meaningful analysis 
increases and; interoperability between various water asset management systems and data sets is facilitated properly.

By overcoming the identified challenges, the company anticipates the following benefits to emerge:

- development of an asset information model that supports all asset management processes (Fig. 1);

- lead the Australia water sector in BIM adoption;

- better risk and uncertainty management;

- better business plans along with asset condition and performance as a result of better asset information processes;

- lifecycle cost saving;

- ability to produce better scenario plans and models;

- customer engagement;

- better informed decision making;

- improved accuracy and consistency of design information;

- improved cost predictability;

- better collaboration between project team members;

- high quality information base for maintaining water facility over the lifetime.

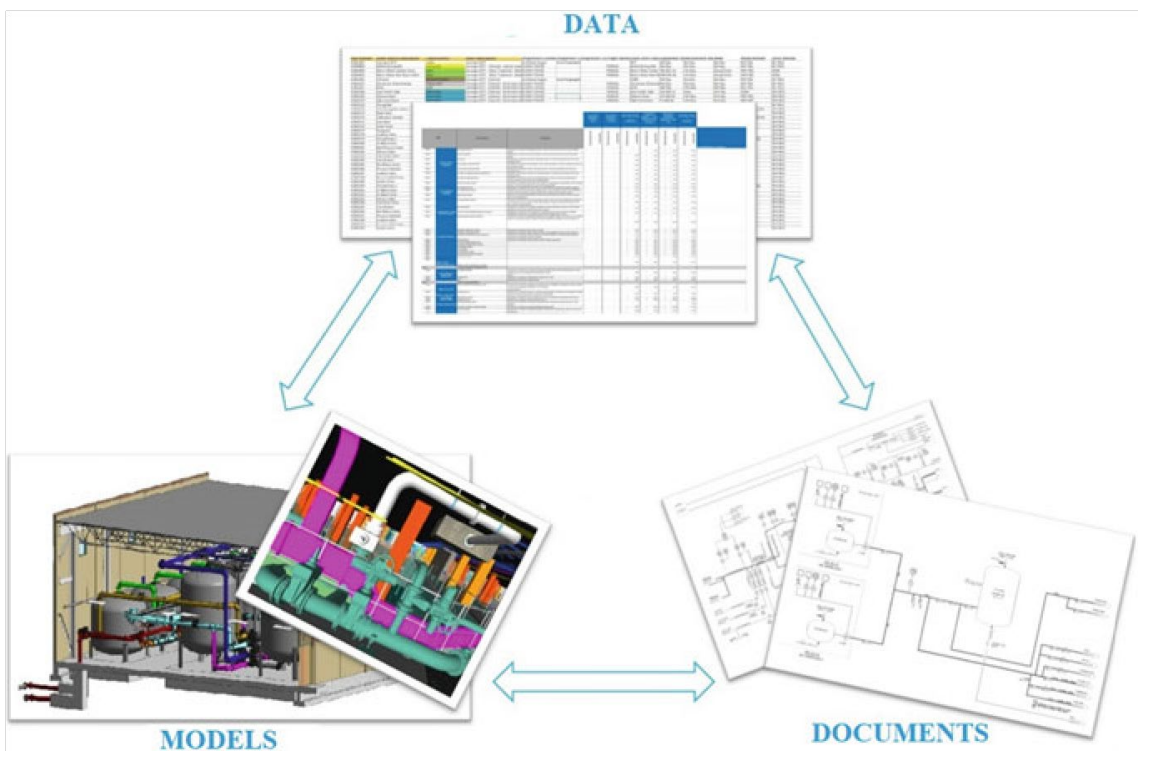

Fig. 1 An anticipated asset information model 


\section{Conclusion}

The main goal of this research was to address the challenge of BIM implementation within the water sector for integrating digital data embedded in water facilities' existing and future proposed digital models across a facility lifecycle. This goal lay in getting participants involved in the various stages of a facilities project (e.g. designers, builders, operators and maintenance staff) to engage with asset managers in an integrated and coherent manner. BIM is not only a 3D model; it is a collaborative process that delivers value, efficiency and safety, recognizing the whole life of asset knowledge and asset lifecycle information management.

Obstructions to the implementation of digital platforms for water asset management were identified, to improve the efficiency of water asset management practices in an Australian water supply company. Overcoming these barriers will enable to develop a necessary strategic direction to transition towards a comprehensive digital asset management agenda. This in turn ensures that awareness of lifecycle thinking and its impact on decision making is better understood by the Australian water industry. Moreover, the digital integration could help achieve economic, social and environmental benefits; enhance the value of assets over their lifecycle; and also provide avenues for educating clients and society on lifecycle thinking.

Further work is associated with providing an asset management agenda that demonstrates the value of lifecycle costing as opposed to short-term thinking. Moreover, there is a need to develop methods to educate water professionals and the broader urban water industry on long-term lifecycle thinking for facilities.

\section{References}

ABAB (2018) Asset information requirements guide: information required for the operation and maintenance of an asset. Australasian BIM Advisory Board, Canberra

ABS (2017) Australian Bureau of Statistics 4610.0 - water account, 2015-16. Australian Government, Canberra

Akcamete A, Akinci B, Garrett JH Jr (2010) Potential utilization of building information models for planning maintenance activities. In: Proceedings of the international conference in computing in civil and building engineering, Nottingham, UK

Araszkiewicz K (2017) Digital technologies in facility management - the state of practice and research challenges. Procedia Eng 196:1034-1042

Becerik-Gerber B, Jazizadeh F, Li N, Calis G (2012) Application areas and data requirements for BIM-enabled facilities management. J Constr Eng Manage 138(3):431-442

Dawood N, Vukovic V (2015) Whole lifecycle information flow underpinned by BIM: technology, process, policy, and people. In: Proceedings of the ICCBEI 
2015 2nd international conference on civil and building engineering informatics, Tokyo, Japan

DSDMIP (2018) Digital enablement for Queensland infrastructure: principles for BIM implementation. The Department of State Development, Manufacturing, Infrastructure and Planning, Brisbane

Hafeez MA, Chahrour R, Vukovic V, Dawood N, Kassem M (2015) Investigating the potential of delivering employer information requirements in BIM enabled construction projects in Qatar. In: Proceedings of the international conference in product lifecycle management, Doha, Qatar Hosseini MR, Roelvink R, Papadonikolaki E, Edwards DJ, Pärn E (2018) Integrating BIM into facility management: typology matrix of information handover requirements. Int J Build Pathol Adapt 36(1):2-14

ISO (2014) Asset management. Overview, principles and terminology

ISO (2018a) Organization of information about construction works-information management using building information modelling. Part 1: Concepts and principles

ISO (2018b) Organization of information about construction works-information management using building information modelling. Part 2: Delivery phase of the assets

Love PED, Matthews J, Simpson I, Hill A, Olatunji OA (2014) A benefits realization management building information modeling framework for asset owners. Autom Constr 37:1-10

Wong JKW, Ge J, He SX (2018) Digitisation in facilities management: a literature review and future research directions. Autom Constr 92:312-326

Yin SJ, Sun XF, Tian, LN, Sun MQ, Li X, Shang YY, Zhang M (2014) The applications of BIM in the building water supply and drainage engineering design. Adva Mat Res 1014:271-275 